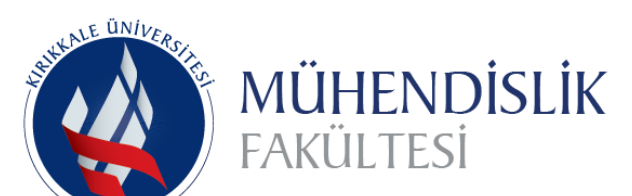

Uluslararası Mühendislik

Araştırma ve Geliştirme Dergisi UMAGD, (2021) 13(3), s256-s265.

International Journal of

Engineering Research and

Development

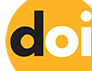

10.29137/umagd.1053602

Cilt/Volume:13 Sayı/Issue:3 Aralık/December 2021 Özel Sayı/ Special Issue

Araştırma Makalesi / Research Paper

Gömülü Sistemler ve Mühendislikte Uygulama Alanları

\title{
Embedded Systems and Application Areas in Engineering
}

\author{
Fuat Türk $^{1}$ iD, Murat Lüy ${ }^{2}$ iD \\ 'Pursaklar Borsa İstanbul Mesleki ve Teknik Anadolu Lisesi, Ankara, Türkiye \\ ${ }^{2}$ Kırlkkale Üniversitesi Elektrik- Elektronik Mühendisliği, Kırıkkale, Türkiye
}

Başvuru/Received: 20/11/2021

Kabul / Accepted: 30/12/2021

Çevrimiçi Basım / Published Online: 31/12/2021

Son Versiyon/Final Version: 31/12/2021

\section{$\ddot{O} \mathbf{z}$}

Günümüzde gömülü sistemler, elektrik-elektronik mühendisliğinin alt kollarından biri olmanın yanı sıra birçok hizmet alanında da kullanılmaktadır. Günümüzde neredeyse Elektronik ve yazılım alanının ortak noktası olan gömülü sistemler bu alanlardaki birçok kişi tarafından öncelikli olarak tercih edilmektedir. Gömülü sistemlerinin programlanması için değişik özellikteki elektronik kartlar ve bilgisayarların desteğine ihtiyaç vardır. Gerek donanımsal bileşenlerin gerekse yazılımsal programlama dillerinin gelişmesi ile birlikte neredeyse tüm mühendislik dallarında gömülü sistemler kullanılmaya başlamıştır. Bu araştırma çalışmasında da gömülü sistemlerin robotik sistemleri, yapay zekâ, tarımsal alanlar gibi birçok mühendislik dallarında tercih edilmesinin nedenlerini örneklerle ele alan kapsamlı bir inceleme yapılmıştır.

\section{Anahtar Kelimeler}

"Gömülü sistemler, Robotik ve yapay zekâ uygulamaları, Mühendislik ve Gömülü Sistemler"

\begin{abstract}
Today, embedded systems are used in many service areas as well as being one of the sub-branches of electrical-electronic engineering. Embedded systems, which are almost the common point of Electronics and software fields, are preferred primarily by many people in these fields. For the programming of embedded systems, the support of different electronic cards and computers is needed. With the development of both hardware components and software programming languages, embedded systems have begun to be used in almost all engineering branches. In this research study, a comprehensive examination has been made those deals with the reasons why embedded systems are preferred in many engineering branches such as robotic systems, artificial intelligence and agricultural fields.
\end{abstract}

\section{Key Words}

"Embedded systems, Robotics and artificial intelligence applications, Engineering and Embedded Systems" 


\section{Giriş}

Gömülü sistemler, bağımsız bir sistem olarak ya da büyük bir sistemin parçası olarak belirli bir görevi icra eden ve kendine özel yazılıma sahip mikroişlemci tabanlı bilgisayar donanım sistemleridir. Gömülü sistemleri insan vücudu gibi düşünebiliriz. İnsan beyni vücutta nasıl birtakım işlemleri yerine getiriyorsa gömülü sistemlerde aynı işlemi mikroişlemci/mikrodenetleyici vasıta ile gerçekleştirmektedirler. Gömülü sistemler, mikro denetleyiciler veya dijital sinyal işlemcileri, uygulamaya özel bütünleşmiş devreler, GPU teknolojisi gibi sistemler üzerinde sıklıkla kullanılır. Bu sistemlerde işletim sistemleri, elektriksel ve mekanik arabirimi işlemeye ayrılmış bileşenler de bütünleşmiş edilerek sistem tasarlanmaktadır. Bu bağlamda ele alındığında gömülü bir sistemin temel yapısı birkaç farklı birimden oluşur. İlk olarak sensor siteminden bahsedilebilir. Sensor, fiziksel büyüklüğü ölçerek elektrik sinyaline dönüştürür. Sonrasında ise gömülü sistem mühendisi veya herhangi bir elektronik cihaz tarafından değerlerin okunması sağlanır. İkinci olarak dönüştürücü sistemi devreye girer. Burada genellikle algılayıcı tarafından gönderilen analog sinyali bir dijital sinyale dönüştürür. Sonrasında ise işlemciler devreye girmektedir. İşlemciler, elde edilen çıktı değerini ölçmek ve bellekte saklamak için kullanılır. Sistemin tasarımına göre tekrardan uygulanmak üzere dijital sinyaller analog sinyallere dönüştürülür. Bu şekilde gömülü bir sistemin kabaca donanımsal ara yüzü oluşturulmuş olur. Şekill. de gömülü bir sistemin donanımsal yapısı örnek olarak gösterilmiştir.

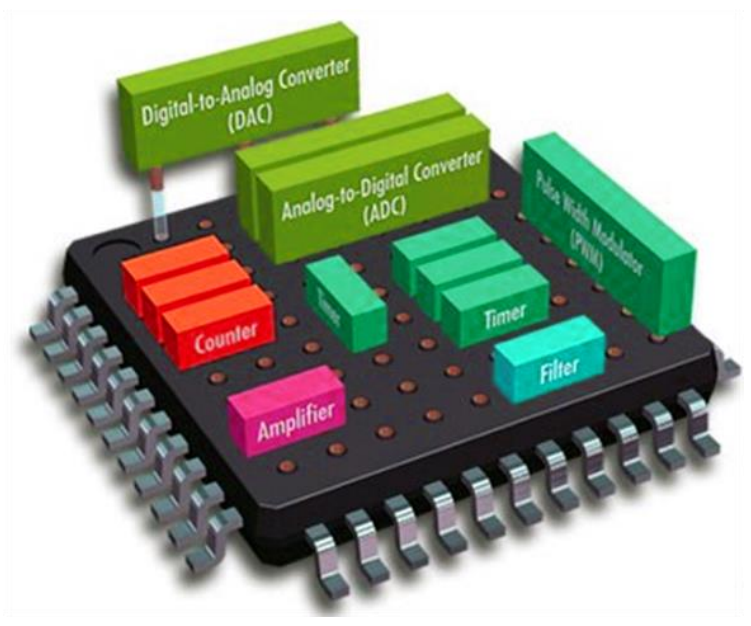

Şekil 1. Gömülü sistemin donanımsal yapısı

Gömülü sistemde kullanılan program dizeleri sistemin yazılım mimarisini oluşturmaktadır. Sıradan bir endüstriyel mikrodenetleyici, dieğr cihazlara oranla sadedir ve bellek kullanımı bir program ortamı ile ilişkilidir. Ayrıca bu sistemler belirli görevleri yerine getirmek üzere tasarlandığı için boyut, güç tüketimi, güvenilirlik ve performansı ayarlamak son derece önemlidir. Bu temel cihazlar CPU'nın makine kodu vasıtasıyla programlanır. Yazılımlar C/C ++ benzeri programlama ortamı ile oluşturulur. Ayrıca, gömülü sistemler çoğu zaman, gerçek zamanlı işletim ortamları ile beraber, gömülü kullanıma uygun ara yüz veya dil platformlarını kullanmaktadır. Örnek olarak Linux, Embedded Java ve Windows IoT gösterilebilir. Yazılım ve donanımın bir araya getirilmesi ile arzu edilen gömülü sistem tasarlanmaktadır. Şekil 2’ de bu yapıya örnek bir tasarım mimarisi gösterilmektedir.
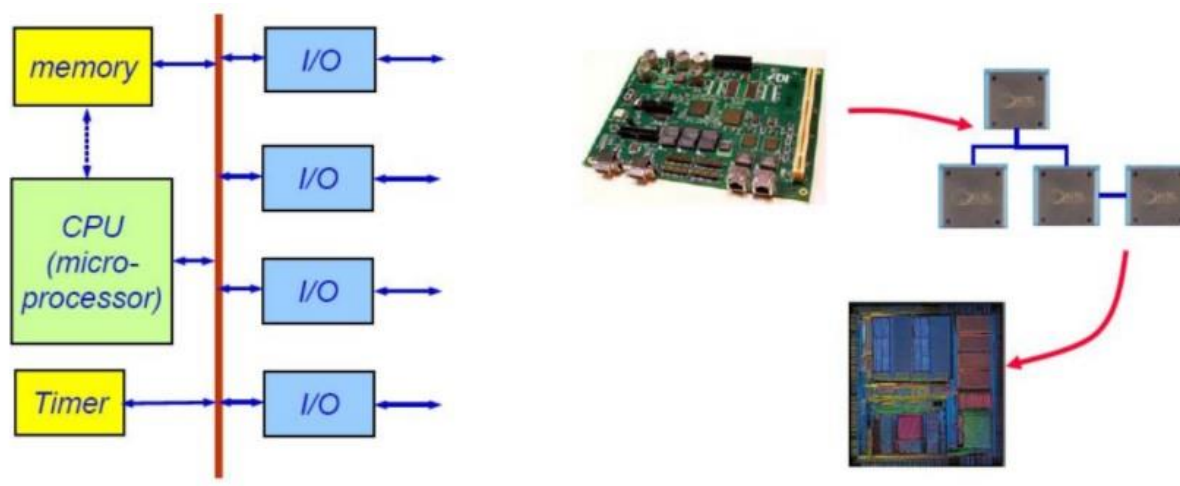

Şekil 2. Gömülü sistemde yazılım ve donanım sistemlerinin birlikte gösterimi 
Şekil 3 'te ise gömülü sistemlerin uygulama alanları ile ilgili bazı görsellere yer verilmiştir.
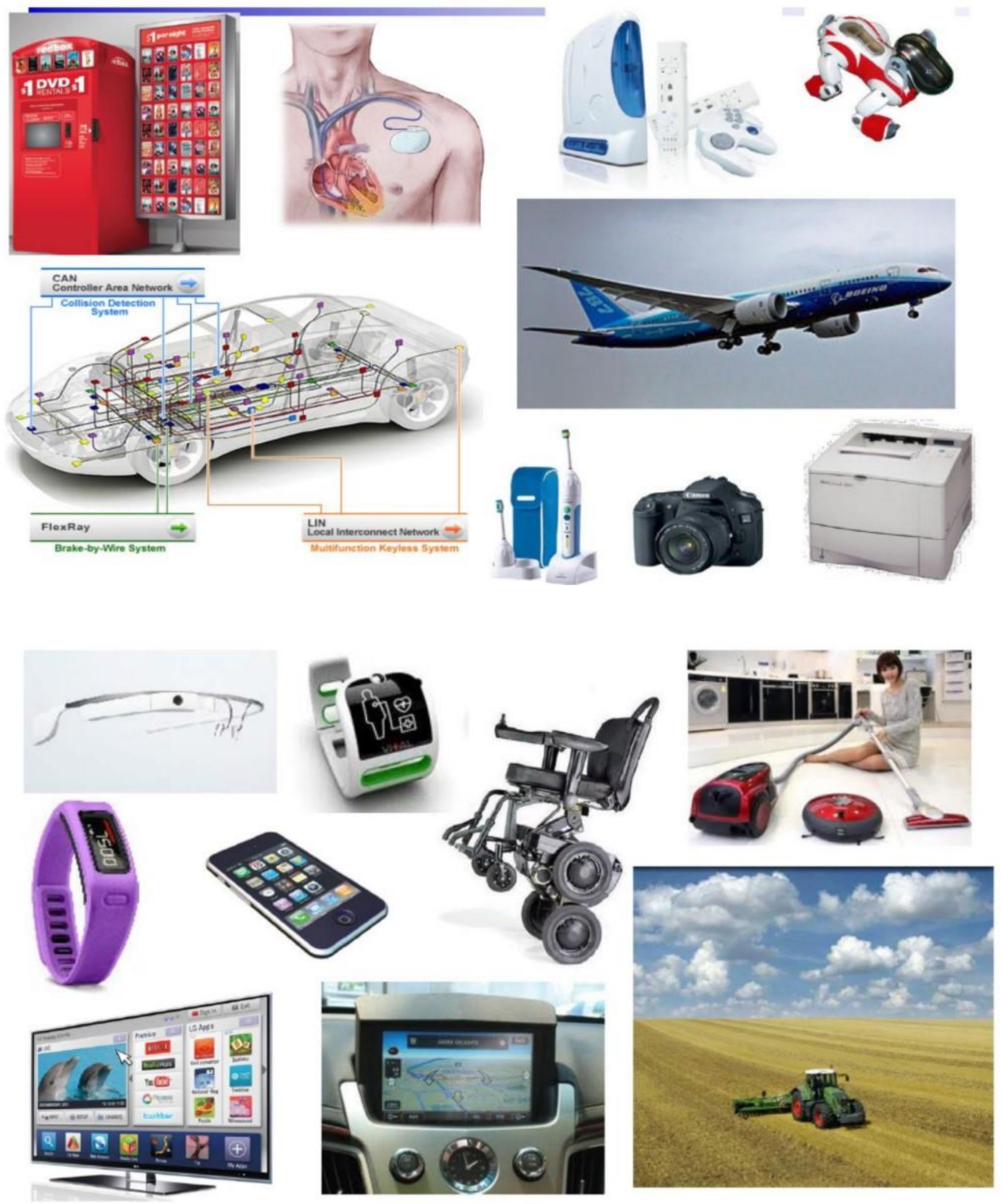

Şekil 3. Gömülü sistemlerin uygulama alanları 
Büyük işlem kapasitesine sahip bilgisayarların işletim sistemleri üzerinde nasıl hata ayıklama işlemi yapılması bekleniyorsa gömülü sistemlerde de aynı durum söz konusudur. Bilgisayar ortamında çalıştırılacak kodun hata denetimi ve güncellemesi yapılabilecek iken gömülü sistemler üzerinde bu şekilde bir hata ayıklama işlemi söz konusu değildir. Çeşitli programlama dilleri sayesinde, mikrodenetleyiciler üzerinde, temel hata ayıklamanın doğrudan çip üzerinde yapılması için gerekli nitelikler vardır. İlaveten, işlemciler genellikle bir hata ayıklama portu vasıtasıyla kontrol işlemi gerçekleştirilecek ve bu sayede program icra edilmesini kontrol eden CPU hata ayıklayıcılarına sahip olabileceklerdir.

Gömülü sistemlerin genel özelliklerini şöyle sıralayabiliriz:

- Genel olarak kısıtlı bir ara yüze sahiptirler veya da ara yüz bulunmamaktadır.

•Güç tüketimi, işlemci gücü, kod boyutu, maliyet, ömür gibi kriterlerin sisteme göre optimize edilmesi zordur.

• Gerçek zamanlı çalışabilme,

• Güvenilirlik,

• Beklenilen yaşam süresi,

- Gerekli yazılımın geliştirilmesi, şeklinde sıralanabilir.

\section{Mühendislikte Gömülü Sistemlerin Uygulama Alanları}

İlk modern, gerçek zamanlı gömülü bilgi işlem sistemi, 1960’larda Apollo Programı için Massachusetts Teknoloji Enstitüsü’nden Dr. Charles Stark Draper tarafından geliştirilen Apollo Rehberlik Bilgisayarı olarak bilinmektedir. Apollo Kılavuz Bilgisayarı, verileri otomatik olarak toplamak görev açısından kritik hesaplamalar sağlamak üzere tasarlanmıştır (Çotuk (2008)).

1971'de Intel, piyasada bulunan ilk mikroişlemci birimi olan Intel 4004'ü piyasaya sürmüş̧ür. Fakat bu işlemci destek yongaları ve harici bellek gerektiren erken bir mikroiş̧lemci olarak karşımıza çıkmaktadır, 1978'de Ulusal Mühendislik İmalatçıları Derneği, programlanabilir mikro denetleyiciler için bir standart yayınlamış ve gömülü sistem tasarımını geliştirmiştir. Daha sonra 1980'lerin başında, bellek, giriş ve çıkış sistemi bileşenleri işlemciyle aynı yongaya entegre edilerek bir mikro denetleyici oluşturulmuştur. Mikrodenetleyici tabanlı gömülü sistemler, kredi kartı okuyucularından cep telefonlarına, trafik kontrol sistemlerinden birçok elektronik küçük ara birime kadar tüketicilerin günlük yaşamlarının her yönüne müdahil olacak şekilde gelişmeye devam etmiştir (Kaya (2008)).

Mikro işlemci tarihindeki bu gelişmeler gömülü sistemler üzerine olumlu yansımıştır. İşlemci teknolojisinin ilerlemesi sayesinde gömülü sistemler üretici firmalar için son derece önemi olan maliyet, karmaşıklık boyutunda oldukça olumlu ilerleme kaydetmiştir. Çünkü gömülü sistemler belli bir amaç için tasarlanıp çok fazla sayıda üretilmektedirler. Bu sebeple gömülü sistemler mühendislik alanında işlemcilerin olduğu her yerde kullanılmaktadır. Bu da gömülü sistemlerin robotik kodlama, yapay zekâ, yazılım mühendisliği gibi birçok alanda tercih edilmesine olanak tanımaktadır.

Gömül sistemler tasarlanırken belli başlı özellikler dikkate alınmalıdır. Bunlar;

- Maliyet hesab1

- $\quad$ Sitemin bellek kapasitesi ve özelliği

- Stabilite

- Güvenlik kaynakları

- Yapılacak işlem karmaşıklığı

şeklinde sıralayabiliriz.

Ayrıca gömülü sistemler yazılımsal tasarım açısından ele alındığında kişisel bilgisayarlardan farklı olarak; 
- Gömülü sistemler daha fazla donanım kaynaklarına ihtiyaç duyarlar.

- Kodun hızlı çalışması ve hafızada kapladığı yer önemlidir. Minimum alan ve zaman, maksimum fayda olması gerekir.

- Makine kodu, assembly dili, yüksek seviyeli diller (c, c++, java,), uygulama düzeyi diller (python, C\#) sırasıyla kullanılabilir.

Bir diğer taraftan Yapay Zekâ, robotik sistemler, Sanal Gerçeklik ve Artırılmış Gerçeklik, makine öğrenimi, derin öğrenme ve Nesnelerin İnterneti’nin (IoT) gibi alanların sürekli gelişimi ile gömülü sistemler endüstrisinin hızla büyümeye devam etmesi beklenmektedir.

\section{3. İlgili Çalışmalar}

Derin sinir ağları ile görüntü sınıflandırma üzerine yapılan bire çalışmada gömülü sistemler kullanılmıştır. Görüntüde algılanan nesnelerin teşhis edilmesi genellikle büyük bir sorun olabilmektedir. Derin öğrenme yöntemlerinin gömülü sistemler üzerinde kullanılması büyük boyutlu fazla hafıza ve gelişmiş işlemci teknolojileri ile mümkün olmaktadır. Bu çalışmada gömülü sistemler vasıtasıyla görüntü sınıflandırma işleminin doğru bir yöntem ile yapıldığı görülmektedir. Bu çalışmada çok az miktarda hafıza kullanarak geliştirilen mimari ile \%85,9 oranında doğruluk değerine ulaşmıştır. Ayrıca mimari 4 saat gibi bir süre zarfinda eğitimini tamamlamış, 0.7 ms içeresinde sınıflandırma sonucuna ulaşabilmiştir (Çalık (2018)).

Çok katmanlı algılayıcı ile yapay sinir ağı kullanılarak plaka tespiti üzerine yapılan bir gömülü sistem çalışmasında yoğoun işlem yükü düşürülerek sistem başarılı bir şekilde çalıştırılabilmiştir. Bu çalışmada plaka yerinin tespit sorunu gömülü sistem alt birimlerinin parelel bir şekilde işlem özelliğini kullanan Alan Programlanabilir Kapı Dizisi (FPGA) üzerinde çalışacak şekilde inşa edilmiştir. Geliştirilen altbirimler görüntü işlem ve örüntü tanıma problemlerinde yaygın bir şekilde kullanılmakta olan görüntü işlem ve sınıflandırıcı birimleridir. Bu altbirimler kenar özellik çıkarma, bit-tabanlı öznitelik elde etme ve yapay sinir ağı sayesinde bir resim aracılı̆ğ ile plaka yerinin bulunması işlevlerini başarı ile tamamlanmıştır. Başarı oranı \%97 seviyesinde olup, YSA'nın donanıma eşleştirilebilmesi için mevcut olan sınırlı bit uzunluğu ve sigmoid fonksiyon yaklaşımları göz önüne alınırsa son derece yüksek başarılı bir sistem olarak düşünülebilir (Çavuşlu et. al (2008)).

“Gömülü Derin Öğrenme ile Tehdit İçeren Nesnelerin Gerçek Zamanda Tespiti” isimli çalışmada X-ray ünitelerinden elde edilen görüntülerde tehdit unsuru olabilecek durumları sınıflandırmak için transfer öğrenme metodu ile gömülü bir sistem olarak çalışabilen bir yapı oluşturulmuştur. Sistem Nvidia TX2 kartı sayesinde bir derin sinir ağı olan Alexnet modeli ile beraber çalışmaktadır. Bu model ile X-ray cihazındaki güvenlik görüntüleri içerisindeki silah, jilet, bıçak gibi tehdit unsuru olabilecek nesneleri sınıflandırılmıştır. Mevcut deney ortamında Alexnet 12.000 görüntü ile eğitim işlemini yerine getirmiş ve gerçek ortamda test edilmiş̧ir. Bu metodun performansı aynı veri seti üzerinde önceden yapılan bilgisayarlı görüntü işleme teknikleri ile mukayese edilmiş ve daha başarılı sonuçlar verdiği gözlemlenmiştir (Aydın et. al (2019)).

"Internet Bağlantılı Gömülü Sistemlerde Güvenlik Açıkları" çalışmasında gömülü sistemlere uzaktan bağlanılıp ve güvenlik zafiyetlerinin araştırılması işlemleri gerçekleştirilmiştir. Bu çalışmada gelişen teknoloji sayesinde mobil aygıtlar ve küçük cihazların elektronik ortamlar ve akıllı şehir platformlarında daha fazla yerde ve daha çok tercih edilmeye başlandığı ifade edilmiştir. Cihazların kullanım süresi arttıkça hatanın ve güvenlik açıklarının zararlarının daha fazla olacağı vurgulanmıştır. Bu tür ürünler, bilgisayarların maruz kaldığı tehditler ile karşılaşırlarsa, bilinen güvenlik standartlarına sahip olmadıkları göz ardı edilmemelidir. Bu yüzden gömülü sistemlerde güvenlik açığını yakalamak oldukça güçtür, ne tür bir açık olduğunu görmek oldukça düşük ihtimallidir. Ayrıca gömülü sistemlere uzaktan değerlendirme ve analiz yapmanın zor olduğu ifade edilmiştir (Efe et. al.(2019)).

"Görüntü İşleme Teknikleri ve Robot Kol ile Nesneleri Kategorilerine Ayırma" isimli yapılan çalışmada gömülü sistem devresi başarılı bir şekilde kullanılmıştır. Bu çalışmada endüstriyel teknolojilideki ilerlemeler ile en kısa sürede en fazla verimli ürünler üretilebildiğinden bahsetmişlerdir. Ayrıca son zamanlarda robot ekipmanlarının ve gömülü sistemlerin beraber kullanımının teknolojinin oldukça ilerlemesine önemli katkı sağladığ ifade edilmiştir. Bu çalışmada bant sistemi üzerinden gelen cisimler bir kamera tarafından taranır ve algılanır. Daha sonra bu nesneler, geliştirilen gömülü sistem yazılımı ile, robot ekipmanı ve görüntü işleyen bilgisayar yazılımı aracılığı ile renklerine göre ayrılarak değişik koordinatlarda bulunan kutulara aktarılarak sinıflandırılmıştır. Geliştirilen bu sistem değişik renklerdeki cisimlerin renk kodlarına göre ilgili kutulara aktarılması işlemini \%100 başarı ile tamamlamıştır (Sarıyıldız ve Demirhan (2015)).

"Görüntü İşleme ve Beş Eksenli Robot Kol ile Üretim Bandında Nesne Denetimi” çalışmada teknolojik bakımdan gelişmekte olan dünya ülkelerinin, endüstriyel sanayi ile birlikte ürünler için; yüksek kalite, düşük maliyet ve zaman tasarrufu gibi parametreleri daha çok ön planda tuttuklarını ifade etmişlerdir. Bu sebeple pek çok sanayi uygulaması için insan gücünde ziyade makine gücü tercih edilerek yapıldığını ifade etmişlerdir. Günümüz sanayisi şartlarında; fazla yük miktarı, devamlı çalışma ve daha az hata gibi 
özelliklerinden dolayı robotlar ve robot ekipmanları daha çok tercih edilmektedirler. Bu çalışmada, bir üretim bandından geçen ürünler, geliştirilen gömülü sistem yazılımı ve robot ekipmanlarının desteğiyle sınıflandırılmıştır. Bahsi geçen bu çalışmada, 15 adet üretim hatası olan ve 45 adet üretim hatası olmayan 60 ürün, \%100 başarı oranı ile ayrıştırılabilmiştir (Şenel ve Çetişli (2015)).

"Nesnelerin İnterneti için Güvenli Ağ Geçidi” isimli gömülü sistem üzerine gerçekleştirilen çalışmada, nesnelerini interneti cihazlarının, endüstriyel gömülü sistemler, akıllı ev aygıtları, sensörler ve daha birçok elektronik cihazların birbirine bağlanması ile oluşturulduğu ifade edilmiştir. İnternet ortamında saldırganlar eğer şifresiz bir iletişim ortamı varsa kullanıcı adı ve parola bilgilerini ağ üzerinden yakalayabilmekte ya da mesaj bilgilerini görüp değiştirebilmektedirler. Bu yapının güvenli hale gelebilmesi için yetkilendirme ve şifreli iletişim şartlarının saplanması gerekir. Ancak, gömülü sistemler simetrik olmayan şifreleme yöntemlerini icra edebilmekte yetersiz kalmaktadırlar. Bu makalede nesnelerin internet ağ geçitleri için güvenli anahtar depolama, 128 bit AES şifreleme ve şifre çözme becerilerine sahip chipi esas alan yeni bir sistem tasarımı önermektedirler. Önerilen çalışma broker ile cihaz arasında kimlik doğrulama ve şifreli iletişim gerçekleştirmesini sağlamaktadır. Ayrıca bu çalışmada ARM Cortex-M3'ün sahip olduğu fiziksel I2C özelliğini kullanan bir yöntem sayesinde iletişim ve şifrelemenin eş zamanda yapılması sağlanmıştır. Bu çalışma için ARM CortexM0 işlemcisini kullanan yeni bir gömülü sistem cihazı tasarlanmış ve demo kart kullanılarak önerilen yaklaşım becerileri performans bilgileri ölçülmüştür. Son olarak, mesajların bütünlüğü korunabilsin diye kriptografik hash (MD5, SHA-1 ve SHA-2) ve çevrimsel fazlalık sınaması algoritmaları kullanılmıştır (Togay et. al. (2019)).

"Energy-saving design of civil engineering buildings based on FPGA and embedded system" çalışmasında İnşaat mühendisleri, özel sektörler de dahil olmak üzere kamuya açık yollar, binalar, havaalanları, tüneller, barajlar, köprüler, su temini ve kanalizasyon arıtma sistemleri mühendislik inşaatı ve bakımını tasarlanması ve inşa edilmesi üzerine gömülü bir sistem üzerinde çalışmışlardır. Bu çalışmada enerjinin inşaat mühendisliği bina tasarımı alanında, zenginlik yaratmak için en katalizörlerden biri olduğundan bahsetmişlerdir. Binaların dünya genelinde toplam enerji tüketiminde önemli bir paya sahip olduğunu; bu nedenle çevreyi derinden etkilediklerinden bahsetmişlerdir. Güç binasının yaşam döngüsü, Alan Programlanabilir Kapı Dizisi (FPGA) ve Gömülü sistem bazında tüm aşamalarda kullanılmıştır. Gömülü sistem genellikle bir inşaat tasarım mühendisliğidir. Ayrıca maksimum bilgi işlem çıktısı, zaman çizelgesi veya iş sürücüleri için ideal bir uygulama şeklidir. Son olarak gömülü sistemlerin binanın yaşam döngüsü, enerji tasarrufu hakkında bilgiler verdiğini ve inşaat mühendisliği alanında binalarının yaşam döngüsü tasarımında yol gösterici ilkeleri açıkladıklarını söylemişlerdir ( Zhang (2021)).

"Design of a Blended e-Learning Curriculum for Embedded System Engineering" çalışmasında gömülü sistemlerin çeşitli ürünlerde uygulanmakta ve bunlara olan talebin oldukça fazla olduğunu dile getirmişlerdir. Ancak, Japonya'da çok ciddi bir gömülü sistem mühendisi sıkıntısı olduğunu, bu nedenle gömülü sistem mühendisliği eğitiminin yaygınlaştırılmasına ihtiyaç duyulmakta olduğunu belirtmişlerdir. Bu çalışmalarında gömülü sistem mühendisliği eğitimi için bir e-öğrenme sistemi geliştirmişler ve bunun e-öğrenme sistemine dayalı bir müfredat olacak şekilde tasarlamışlardır. Bu eğitim sistemi, uzaktan uygulama sistemi ve çevrimiçi donanım tanımlama dili (HDL) tasarım kontrol sistemi de dahil olmak üzere evde kendi kendine öğrenmeyi teşvik etmek için bazı etkili materyallere sahiptir. Bu eğitim sistemini kullanarak bazı eğitim kursları gerçekleştirip devamında sonuçlarını değerlendirmişlerdir (Chiba et. al (2010))."Software Engineering for Embedded and Real-Time Systems " çalışmasında özellikle son yıllarda, bilgi işlem dünyasının büyük, statik, masa üstü makinelerden küçük, mobil ve gömülü cihazlara geçtiğini belirtmişlerdir. Bu zamanda önceki senaryoda başarıyla uygulanmış olan yazılım sistemlerini geliştirmeye yönelik yöntemler, teknikler ve araçlar, ikinci senaryoda o kadar kolay uygulanabilir değildir. Mobil, gömülü cihazların ağlarında çalışan yazılım sistemleri, daha geleneksel sistemlerde her zaman gerekli olmayan özellikler sergileme zorunluluğu olduğundan bahsetmişlerdir (Oshana (2019)).

"Basic human-robot interaction system running on an embedded platform" çalışmasında Robotik uygulamaların gelecek nesiller boyunca toplumda baskın bir alan olacă̆ ifade edilmiştir. Çeşitli görevlerin yerine getirilmesini kolaylaştıran cihazlar ve mekanizmalar ile günlük yaşam ortamlarının çoğunda ve makinelerin giderek daha fazla iş gerçekleştirdiği çalışma senaryolarında varlığ şu anda artmaktadır. Toplumda otonom robotik sistemlerin varlığındaki bu artış, esas olarak sensör ve aktüatör sistemlerinin muazzam hassasiyeti sayesinde insan kapasitesine kıyasla büyük verimlilik ve güvenliklerinden kaynaklanmaktadır. Bunlar arasında görüntü sensörleri son derece önemlidir. İnsanlar ve birçok hayvan doğal olarak güçlü algı sistemlerinden hoşlanır, ancak robotikte bu, sürekli bir araştırma hattı oluşturur. Akıl yürütme ve karar verme için yüksek bir kapasiteye sahip olmanın yanı sıra, bu robotlar, bu yeni sanayi devriminin çalışma ortamlarında etkin bir şekilde etkileşime girmelerine izin vererek, algı sistemlerinde önemli gelişmeler içermektedir. Yüze bakarak insanlar arasındaki en temel etkileşimden yola çıkarak, otonom ve kendin yap robotu için geliştirilen bu makalede yenilikçi bir sistem sunulmaktadır. Bu sistem üç modülden oluşmaktadır. 
İlk olarak, mevcut görüntüdeki insan yüzlerini algılayan yüz algılama bileşeni. İkincisi, kullanılan tek kameradan daha geniş bir görüş alanı sunan sahne temsil algoritması, bir servo-pan ünitesine monte edilmiştir. Üçüncüsü, iki rakip dinamiğe göre tasarlanan ve uygulanan aktif bellek bileşeni: yaşam ve belirginlik. Algoritma, yeni yüzler bulmak, mevcut yüzleri takip etmek ve artık sahnede görünmeyenleri unutmak amacıyla servo-pan ünitesini akıllıca hareket ettirir. Sistem, Raspberry Pi3 kartına dayalı düşük maliyetli bir platform kullanılarak geliştirilmiş ve doğrulanmıştır (Vega (2021)).

"Research on Arm Embedded System for Football Robot" çalışmasında hediye çarpışma masa oyunu oynamak için iki dereceden oluşan robot tasarımı, üretimi ve gerçek zamanlı çalışan birincil kontrollü gömülü sistemi gerçekleştirilmiştir. Bilgi işlem ve iletişim birimi yüksek çözünürlüklü dijital kameralardan biridir. Robot, iki servo motor ve bir darbe mekanizmasından oluşmaktadır. Sisteme üç önemli unsur dahil edilecektir. Platformda kamera görüntüyü alır ve merkez ofise gönderir. Fotoğraf işleme ve önemli verileri yakalamak için uyarlanabilir harita teknolojisini kullanmaktadır. Dosya satın alınan ürünü entegre edecektir; Seri bir arayüz üzerinden mikrodenetleyiciye bu bilgiler iletilecektir. Negatifi daha iyi koordine etmek için orta mesafe ve açılar için motor sürücü kontrol algoritması ve ortogonal sıkıştırma kodeği kullanılmıştır. Disk veya kale direği ile aynı hizada olduğunda, etkileyici bir birim ve atış yaptığında, ateşleme pimi kuvveti kontrol edecektir. Oyuncular, ayağından üretilen maksimum gücü kale direğine atacaklardır. Bu sistemde ki nihai amaç, akıllı eğlence teknolojisi konseptini karşılayan, uygun maliyetli, kullanıcı dostu bir sistem geliştirmektir (Zhou ve $\operatorname{Li}(2021))$.

"DeWaLoP In-pipe Robot Embedded System" çalışması DewaLoP (Geliştirme Su Kaybını Önleme) robot sisteminde uygulanan bir boru içi robot gömülü sistemin geliştirilmesini anlatmaktadır. Gömülü bir sistemi, tanımlanmış bir görevi bir mikroçip içine alınmış gibi yerine getirmek için CPU kartlarının, çevre birimlerinin ve iletişim protokollerinin yapılandırılması olarak tanımlanmaktadır. DeWaLoP boru içi robotunun görevi, Viyana ve Bratislava'nın tatı su sistemlerinin boru bağlantı boşluklarını yeniden geliştirmektir, robot borunun içinde hareket edebilmeli, bu boru bağlantılarını kapatmak için bir restorasyon malzemesi temizleyebilmeli ve uygulayabilmelidir. Önerilen gömülü sistem, boru içi robotun işlevselliği ve sistem çalışması üzerine tasarlanmıştır, sonlu durum makinesini (FSM) taklit eder, burada robot modülleri her durumda bağımsız olarak veya başka modüller ile birlikte çalışacak şekilde yapılandırılır (Mateos ve Vincze (2012)).

"Design of a 4 DOF parallel robot arm and the firmware implementation on embedded system to transplant pot seedlings" çalışmasında 4 DOF paralel robot kolunu sürmek için gerçek zamanlı gömülü bir sistem üzerinde bir ürün yazılımı tasarımı ve uygulamasını sunulmaktadır. Yazılım, robot kolunun hareketini üretmek için temel olarak iki bileşenden oluşmaktadır: a) sürekli konum koordinatlarının oluşturulması ve b) harekete geçirme sinyallerinin oluşturulması. Bu iki bileşen, ortak bir iletişim veriyoluna sahip iki farklı mikro denetleyicide işlenmiştir. Konum oluşturma algoritması, kullanıcı tarafından mikrodenetleyicinin EEPROM belleğinde daha önce saklanan giriş konumlarını okuyarak sürekli konum verilerini G-kod dizileri şeklinde hareket üretme algoritmasına iletir ve iletir. Bir el sıkışma sinyalinin alınması, bir iletişim veriyolu aracılı̆̆ıyla bu bileşenler arasındaki veri iletimini senkronize etmiştir. Robot hedef koordinatlarını ayarlamak için kullanıcı ile iletişim kurmak için insan-makine arayüzü (HMI) olarak bir LCD ekran ve tuş takımı kullanılmıştır. Robot kolunun mekanik yapısı, kademeli motorlar tarafından harekete geçirilen çoklu bağlantılardan oluşmaktadır. Çalışma alanı sınırı, limit anahtarları tarafından algılanmışıı. Kinematik denklemler, karşılık gelen giriş eklem açıları için kavrayıcı konumunu temsil etmektedir. Robot eklemlerinin eşzamanlı hareketi için harekete geçirme sinyalleri üretmek için hareket üretme algoritması yardımıyla robot kolunun kinematik denklemlerini hesaplamak için bir mikro denetleyici kullanılmıştır. Kinematik denklemler, gerçek zamanlı işletim sistemi (RTOS) kullanılarak mikrodenetleyicinin çift çekirdekli özelliği ile çözülmüş, bu da hesaplamayı adım başına ortalama $198 \mu$ s'lik bir hesaplama süresi ile daha hızlı hale getirmiştir. Geliştirilen ürün yazılımı, saksı fidelerinin ölçümünü otomatikleştirmek için kâğıt kap fidelerinin sürekli olarak alınması ve yerleştirilmesi için gömülü mikro denetleyiciler kullanılarak 4 DOF paralel manipülatör üzerinde uygulanmış ve test edilmiştir. Her bir fidenin toplanıp bırakılması için geçen çevrim süresi $3.5 \mathrm{~s}$ olup başarı oranı \%93,3'tür (Rahul 2020).

“Autonomous Tour Guide Robot using Embedded System Control” çalışmasında ziyaretçilere Asya Pasifik Üniversitesi Mühendislik Laboratuarlarında rehberlik etmek için tasarlanmış etkileşimli bir otonom tur rehberi robotunu açıklamaktadır. Haritalama gibi çeşitli kendi kendine yerelleştirme yeteneklerine sahip tur rehberi robotları geçmişte tanıtılmış olsa da, bu teknolojilerin performansı hala iç mekan navigasyon engelleri tarafından sorgulanmaya devam etmektedir. Mevcut yaklaşım, Raspberry pi 2 olan gömülü bir sistem üzerinde çalışan düşük maliyetli, otonom bir iç mekân tur rehberi robotunun uygulanmasından oluşmaktadır. Otonom navigasyon, ultrasonik sensörler ve basit bir web kamerası kullanılarak görüntü işleme kullanılarak duvar izleme yoluyla gerçekleştirilir. Tanıtılan bit düzeyinde görüntü işleme karşılaştırma yöntemi OpenCV'de yazmaktır ve Raspberry pi'de çalışır. Görüntüleri alır ve her bir laboratuvarı tanımlamak için etiketleri arar. Laboratuvarlarda yapılan navigasyon testleri sırasında \%98 tanıma doğruluğu elde edilmiştir. Kullanıcı etkileşimi, robotun üzerine yerleştirilen bir android tablet üzerinde ses tanıma ile sağlanmıştır. Robot ve ziyaretçiler arasındaki iletişim için Google konuşma tanıma API'leri kullanılmıştır (Diallo et. al. (2015)). 
"A calibration method of 2D LIDAR-Visual sensors embedded on an agricultural robot" çalışmasında Robotik alanında, mobil platformlar tipik olarak birden fazla sensörden gelen verileri birleştirmiş ve kapsamlı bir şekilde araştırılmıştır. Sensörler arasındaki homojen dönüşümü tahmin etmenin, ölçüm verilerini ilişkilendirmede kritik bir adım olduğu vurgulanmıştır. Bu yazıda, çilek serası uygulamaları için tasarlanmış bir tarım robotuna yerleştirilmiş 2D LIDAR-Visual sensörlerin kalibrasyon yöntemini sunulmuştur. Yöntem, plandan plana homografi yaklaşımına dayanır ve bir dizi nokta denkliği kullanır. Karşılık noktaları, lazer mesafe bulucu düzleminin kalibrasyon modelinin kenarlarıyla ölçülen kesişme noktalarıdır. Çıkarılan noktalar, homografi matrisini tahmin etmek için kullanılır. RANSAC algoritması, sağlam bir homografi oluşturmak için sensörler tarafından çift taramalardan/görüntülerden elde edilen daha fazla nokta ile kullanılır. Tahmini homografi matrisi, 2D LIDAR ve monoküler kamera arasındaki katı dönüşüm olarak tanımlanır. Önerilen yöntemin sonuçları, önceden içsel parametrelere veya karmaşık kalibrasyon nesnelerine olan ihtiyacı ortadan kaldırarak doğru dışsal parametrelere ulaşabileceğimizi göstermektedir. Sistem, Hokuyo URG-04LX-UG01 sensöründen ve kızılötesi filtreli bir monoküler kameradan oluşur. Tüm yazılım modülleri Robot İşletim Sistemi (ROS) ve Python kullanılarak oluşturulmuştur (Abanay et. al. (2022)).

"Vision systems for harvesting robots: Produce detection and localization" çalı̧̧masında Son birkaç yılda, yapay zekanın kullanımı ve derin öğrenme, yeni 3D özellikli sensörler ve uç bilgi işlem gömülü sistemler gibi teknolojik gelişmeler, hasat robotları için ürün algılama ve yerelleştirme performansını artırdığını ifade etmişlerdir. Ne yazık ki, bu performans artışı genellikle manuel olarak etiketlenmesi gereken büyük veri kümeleri, eğitim için uzun süreler, artan işlem süresi ve çıkarım gücü ve algılama modellerini çalıştırmak için yüksek maliyetli güçlü donanım gerektirmektedir. Bu çalışma, kullanılan yeni teknolojiye özel önem vererek, ürün tespiti ve yerelleştirme araştırmalarına odaklanarak, hasat robotlarının görüş alt sistemlerinin durumu hakkında güncel bilgiler sağlamaya odaklanmaktadır. Tespit ve yerelleştirme metodolojileri üretmek için bu teknolojiyi tanıtmanın zorluklarının bir açıklaması ve analizi de bu derlemede mevcuttur. Son olarak, hasat robotlarının görüş alt sistemleri için gelecekteki eğilimler açılanmış ve tartışılmıştır (Montoya-Cavero et. al (2022)).

"Embedded Architecture Composed of Cognitive Agents and ROS for Programming Intelligent Robots" çalışmasında, akıllı robotları programlamak için bir alternatif olarak hizmet eden Robotik İşletim Sistemi (ROS) ile iş birliği içinde bilişsel ajanların kullanımını teşvik etmeyi amaçlayan gömülü bir mimari önerilmekte ve değerlendirilmektedir. Programlama soyutlama seviyesini iki yönde destekler. İlk yön, algılarından ve ilgili eylemlerinden oluşan robot zekasını programlamak için bilişsel ajanların olanaklarını kullanmakla ilgilidir. İkinci yön, robot etkileşimini sensörleri ve aktüatörleri ile programlamak için ROS katmanlarını kullanma olanaklarından yararlanır. Makale, önerilen mimarinin faydalarını değerlendirmemize izin veren performans ölçümlerini ölçerken, simüle edilmiş İHA'ları komuta etmek için aracıları kullanma deneylerini rapor etmiştir (Sliva et. al (2020)).

“Application of Face Recognition Method Under Deep Learning Algorithm in Embedded Systems” çalışmasında Derin öğrenmeye dayalı Evrişimli Sinir Ağı $(\mathrm{CNN})$, iki derin yüz algılama algoritması önermek ve derin öğrenme algoritmasını yüz algılamaya uygulamak ve gömülü yüz tanıma sistemini keşfetmek için gömülü bir yüz tanıma sistemi tasarlamak için tanıtılmıştır. İlk olarak, OMTCNN olarak belirtilen yüz görüntüsünün simülasyon dönüşümü ve kırpma ön işlemesi için optimize edilmiş bir Çok Görevli Basamaklı Evrişimsel Ağ (MTCNN) algoritması önerilmiştir. İkinci olarak, gömülü sistemdeki LCNN olarak adlandırılan yüz tanımanın hesaplama karmaşıklığını azaltmak için CNN'ye dayalı hafif bir yüz tanıma algoritması önerilmiştir. Son olarak, OMTCNN ve LCNN, çok çekirdekli gömülü yüz tanıma sistemini oluşturmak için birleştirilir. Sonuçlar, OMTCNN'nin yüz kimliğini belirlemede iyi bir performans gösterdiğini ve eğitim doğruluğunun, geliştirilmemiş MTCNN algoritmasından önemli ölçüde daha iyi olan \% 95,78 'e ulaşabileceğini göstermektedir. Labeled Faces in the Wild (LFW) veri setinde, LCNN \%98,13'lük doğru bir oran sağlar ve modelin karmaşıklığındaki azalma, hesaplama hızını 6,4 kata kadar artırır. Test sonuçları, tasarlanan yüz tanıma sisteminin gömülü platformda iyi bir uygulanabilirliğe sahip olduğunu göstermektedir. Yüz tanıma modülünün doğruluğunun artması ve hesaplama hızlandırma modülünün kullanıma sunulması, gömülü sistemin yüz algılama ve tanıma performansını önemli ölçüde iyileştirmiştir. Derin öğrenmeye dayalı gömülü yüz tanıma sisteminin pratik uygulama değeri vardır. Bu makale, akıllı robotları programlamak için bir alternatif olarak hizmet eden Robotik İşletim Sistemi (ROS) ile iş birliği içinde bilişsel ajanların kullanımını teşvik etmeyi amaçlayan gömülü bir mimariyi önerir ve değerlendirir. Programlama soyutlama seviyesini iki yönde desteklemektedir. İlk yön, algılarından ve ilgili eylemlerinden oluşan robot zekasını programlamak için bilişsel ajanların olanaklarını kullanmakla ilgilidir. İkinci yön, robot etkileşimini sensörleri ve aktüatörleri ile programlamak için ROS katmanlarını kullanma olanaklarından yararlanır. Makale, önerilen mimarinin faydalarını değerlendirmemize izin veren performans ölçümlerini ölçerken, simüle edilmiş İHA'ları komuta etmek için aracıları kullanma deneylerini rapor edilmiş̧ir (MingxiaSu ve Wang (2021)). 
"Enhancing image processing architecture using deep learning for embedded vision systems" çalışmasında son yıllarda gömülü vizyonun başarısı ve yetenekleri gömülü uygulamalarda kendini gösterdğinden bahsedilmiştir. Gömülü tıbbi uygulamalar gibi elektronik cihazlara vizyonun yerleştirilmesi, yüksek performanslı işlemcilerin mevcudiyeti, derin öğrenme algoritmalarıyla bütünleşme ve görüntü işleme teknolojisindeki ilerlemeler tarafindan yönlendirilmektedir. Ancak, gömülü görüntü sistemlerinde görüntü işleme dahil olmak üzere, bir nesneyi algılamak için tek bir görüntüyü işlemek için bile çok büyük miktarda hesaplama yeteneği gerekir ve gömülü sistemlerde uygulanması son derece zordur. Derin öğrenme algoritmalarını uygulamak ve onu göreve özel bir veri setinde test etmek, gelişmiş sonuçlar sağlayabilir. Bu yazıda, gömülü görüntü sistemleri için derin öğrenme kullanarak görüntü işleme mimarisini geliştirmeye yönelik bir yaklaşım önerilmiş ve analiz edilmiştir. Derin öğrenme algoritmalarını uygulamak ve gömülü vizyon üzerinde test etmek etkili sonuçlar vermiştir (Udendhran et. al. (2020)).

"A deep learning framework with an embedded-based feature selection approach for the early detection of the Alzheimer's disease" çalışmasında yaşlanma, ilerleyici bir bunama şekli olan Alzheimer hastalığı (AH) dahil olmak üzere çeşitli rahatsızlıklarla ilişkili olduğu ifade edilmiştir. Bu hastalığın semptomları yıllar içinde gelişir ve ne yazık ki tedavisi yoktur. Mevcut tedavileri yalnızca semptomların ilerlemesini yavaşlatabilir ve bu nedenle hastalığı erken bir aşamada teşhis etmek kritik öneme sahiptir. AH'nin erken teşhisini iyileştirmeye yardımcı olmak için, AH hastalarını sınıflandırmak için gömülü bir özellik seçimi yaklaşımına sahip derin öğrenmeye dayalı bir sınıflandırma modeli kullanılmıştır. Analiz için GEO omnibus veri tabanından bir AD DNA metilasyon veri seti (34 vaka ve 34 kontrol içeren 64 kayıt) kullanılmıştır. İlgili özellikleri seçmeden önce, veriler kalite kontrol, normalizasyon ve aşağı akış analizi yapılarak ön işleme tabi tutulmuştur. İlişkili $\mathrm{CpG}$ sitelerinin sayısı çok fazla olduğundan, dört gömülü tabanlı özellik seçim modeli karşılaştırılmış ve önerilen sınıflandırma modeli için en iyi yöntem kullanılmıştır. Bir Gelişmiş Derin Tekrarlayan Sinir Ağı (EDRNN) uygulanmış ve bir Evrişimsel Sinir A $\breve{g} 1(C N N)$, bir Tekrarlayan Sinir Ağı (RNN) ve bir Derin Tekrarlayan Sinir Ağı (DRNN) dahil olmak üzere diğer mevcut sınıflandırma modelleriyle karşılaştırılmıştır. Sonuçlar, önerilen modelin sınıflandırma doğruluğunda diğer yöntemlere kıyasla önemli bir gelişme göstermiştir (Mahendran ve Vincent (2021)).

\section{Sonuç ve Tartışma}

Yapılan araştırma makalesinde gömülü sistemlerin temel özellikleri ve çalışma prensipleri açıklanmıştır. Daha sonra mühendislik alanında ki özelliklerinden bahsedilmiştir. Literatür çalışmasında yapay zekâ başta olmak üzere derin öğrenme ile beraber kullanım alanları, robotik sistemler ile beraber kullanım alanları, turizm seyahat, inşaat, eğitim gibi birçok alanda yapılan uygulamalardan bahsedilmiş̧tir. Bahsedilen uygulama alanlarında gömülü sistemlerin nasıl kullanıldı̆̆ı ve hangi yöntemlerin tercih edildiği açıklanmıştır.

Elde edilen bilgiler ışığında gömülü sistemlerin üstün özellikleri tespit edilmekle beraber uygulamada karşılaşılan zorlukları da ifade edilmiştir. Bu bilgiler doğrultusunda takip edilen süreçte derin öğrenme ve robotik sistemleri kapsayan gömülü bir sistem tasarlayıp özellikle tıp alanında hastalık tanı ve teşhisi için ucuz maliyetli, düşük işlem kapasiteli ve hızlı netice veren hibrid bir yapı oluşturmayı planliyoruz.

\section{Referanslar}

Abanay, A., Mamoudi, M., Ensari, M. (2022). A calibration method of 2D LIDAR-Visual sensors embedded on an agricultural robot. Optik, 249, 168254.

Adan, O.C.G. (1994). On the fungal defacement of interior finishes, $\mathrm{PhD}$ thesis, Eindhoven University of Technology, Eindhoven, The Netherlands.

Aydın, İ., Salur, M.A., Karaköse, M. (2019). Gömülü Derin Öğrenme ile Tehdit İçeren Nesnelerin Gerçek Zamanda Tespiti, DÜMF Mühendislik Dergisi 10(2,) pp. 497-509.

Chiba, S., Yonamine, T., *Sasaki, M., Sugawara, K.anomata, A. Design of a Blended e-Learning Curriculum for Embedded System Engineering, IFAC Proceedings Volumes, 42, Issue 24, pp. 152-157.

Çalık, R. (2018). Gömülü Sİstem Üzerİnde evrişimsel sinir ağları ile Nesne Sınıflandırılması, Yüksek Lisans Tezi, TOBB Ekonomi ve Teknoloji Üniversitesi, Ankara, Türkiye.

Çavuşlu, M.A., Karakaya, F., Altun H. (2008). ÇKA ipi Yapay Sinir Ağı Kullanılarak Plaka Yeri Tespitinin FPGA'da Donanımsal Gerçeklemesi, Akıllı Sistemlerde Yenilikler ve Uygulamaları Sempozyumu (ASYU).

Çotuk, H. (2008). Pıc Mikrodenetleyiciler İçin Gerçek Zamanlı İşletim Sistemi, Yüksek Lisans Tezi, TOBB Ekonomi ve Teknoloji Üniversitesi, Ankara, Türkiye. 
Diallo, A.D., Gobee, S., Durairajah, V. (2015). Autonomous Tour Guide Robot using Embedded System Control, Procedia Computer Science, 76, pp. 126-133.

Efe, A., Sarıkaya M., Altınbaş, M. (2019). Internet Bağlantılı Gömülü Sistemlerde Güvenlik Açıkları. Erzincan Üniversitesi Fen Bilimleri Enstitüsü Dergisi, 12(3), 1468-1484.

Kaya, A. (2008). Gömülü sistemler ve uygulama alanları. Çanakkale Onsekiz Mart Üniversitesi, Akademik Bilişim, Çanakkale.

Mahendran, N., Vincent, D.R. (2021). A deep learning framework with an embedded-based feature selection approach for the early detection of the Alzheimer's disease, Computers in Biology and Medicine, 105056.

Mateosi L.A., Vincze, M. (2012). DeWaLoP In-pipe Robot Embedded System. IFAC Proceedings Volumes, 45, Issue 22, pp. 842847.

MingxiaSu, X.,Wang,Z., (2021). Application of Face Recognition Method Under Deep Learning Algorithm in Embedded Systems, Microprocessors and Microsystems, 104034.

Montoya-Cavero, L.E., León, R.C., Alfonso, T.G, Cabello, J.A. (2022). Vision systems for harvesting robots: Produce detection and localization, Computers and Electronics in Agriculture, 192, 106562.

Oshana, R. (2019). Software Engineering for Embedded and Real-Time Systems, Methods, Practical Techniques, and Applications, pp. 1-31.

Rahul, K, Raheman H, Paradkar, V. (2020). Design of a 4 DOF parallel robot arm and the firmware implementation on embedded system to transplant pot seedlings, Artificial Intelligence in Agriculture,4, pp. 172-183.

Sarıyıldız, S.Ö., Demirhanİ A. (2015). Görüntü İşleme Teknikleri ve Robot Kol ile Nesneleri Kategorilerine Ayırma, Uludağ Üniversitesi Mühendislik Fakültesi Dergisi, Cilt 26, Sayı 2

Silva, G.R., Becker, B.E., Hübner, J.F., (2020). Embedded Architecture Composed of Cognitive Agents and ROS for Programming Intelligent Robots, IFAC-PapersOnLine,53, Issue 2, pp. 10000-10005.

Şenel, F.A., Çetişlii B. (2015). Görüntü İşleme ve Beş Eksenli Robot Kol ile Üretim Bandında Nesne Denetimi. Pamukkale Univ Muh Bilim Dergisi, 21(5), 158-161.

Togay, C.A., Mutlu G., Kurtuluş, D., Özgür, F. (2019). Secure Gateway for the Internet of Things, Avrupa Bilim ve Teknoloji Dergisi Sayı 16, S. 414-426.

Udendhran, R., Balamurugan,M., Suresh, A., Varatharajan, R, (2020). Enhancing image processing architecture using deep learning for embedded vision systems, Microprocessors and Microsystems, 76, 103094.

Vega, J. (2021). Basic human-robot interaction system running on an embedded platform, Microprocessors and Microsystems, Volume 85, pp. 104316.81 , pp. 103776.

Zhang, X., (2021). Energy-saving design of civil engineering buildings based on FPGA and embedded system, Microprocessors and Microsystems, Volume 83, pp. 103970.

Zhou, M., Li, D., (2021). Research on Arm Embedded System for Football Robot, Microprocessors and Microsystems 